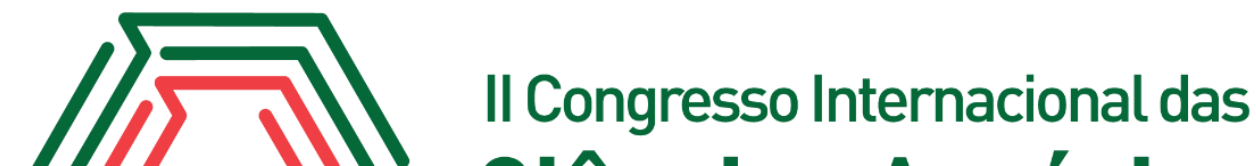 Ciências Agrárias COINTER - PDVAgro 2017
}

\section{AVALIAÇÃo DO DESENVOLVIMENTO dE PARTE AÉREA DE PLÂNTULAS DE Canavalia ensiformis (L) DC EM DIFERENTES CONCENTRAÇÕES DE BIOCHAR.}

\author{
Apresentação: Pôster
}

Yanka Beatriz Costa Lourenço ${ }^{1}$; Stephanni Ingrid de Souza Silva ${ }^{2}$; Elias Costa de Souza ${ }^{3}$; Alexandre Santos Pimenta ${ }^{4}$

\section{Introdução}

Canavalia ensiformis (L.) DC, é conhecida popularmente como feijão-de-porco, originada na América, ocorre em regiões tropicais e subtropicais devido a sua resistência às altas temperaturas e a seca, não suportando geadas e sombreamento parcial (LÓPEZ, 2012.).

A adição de carvão ao solo, conhecido como biochar, em frações similares a de areia, silte e argila, pode alterar a consistência e porosidade, melhorar a capacidade de retenção de água, melhorar a textura, profundidade, densidade, elevar o $\mathrm{pH}$ e ainda ajudar no desenvolvimento de plantas. (PAZ, 2013; CAMPOS, 2015).

Diante a discussão e o abrangente estudo da influência do biochar no desenvolvimento de várias espécies, o objetivo do trabalho foi analisar o desenvolvimento da parte aérea de Canavalia ensiformis (L.) DC em diferentes concentrações de carvão vegetal no substrato.

\section{Fundamentação Teórica}

A adição de biochar ao solo melhora a sua fertilidade e o rendimento das culturas em solos agrícolas, pois ocorre a estimulação dos organismos do solo que consequentemente ocorre um aumento da reciclagem de nutrientes presos nos resíduos de biomassa. (NÓBREGA 2011).

\section{Metodologia}

\footnotetext{
${ }^{1}$ Engenharia Florestal, UFRN, yankalourenco97@gmail.com

2 Engenharia Florestal, UFRN, stephanniflorestal@gmail.com

${ }^{3}$ Engenheiro Florestal, UFRN, eliasrem@hotmail.com

${ }^{4}$ Prof. Associado I - Engenharia Florestal, UFRN, alexandre_spimenta@hotmail.com
} 
O experimento foi realizado no Viveiro de Mudas da Pós-graduação em Ciências Florestais, localizado na Área de Experimentação Florestal da Unidade Acadêmica Especializada em Ciências Agrárias (UEACIA), da Universidade Federal do Rio Grande do Norte (UFRN), Campus MacaíbaRN.

As sementes do Feijão-de-Porco são provenientes da Universidade Federal Rural do Semiárido - UFERSA. Foram utilizados 16 baldes preenchidos com o mesmo substrato de 0,0565 $\mathrm{m}^{3}$ de esterco e areia, na proporção de 2 para 1 . O carvão vegetal utilizado foi proveniente da carbonização do Eucalyptus. Para a realização da mistura do carvão ao substrato foi necessário moer o material em uma forrageira e passada em peneira metálica de 40 mesh para que a granulometria fosse uniforme em todos os baldes.

O delineamento experimental foi inteiramente casualizado e consistiu em 3 dosagens de carvão C0-0; C1- 84,75g/balde; C2- 169,50 g/balde; C3-254,25 g/balde, com 4 repetições por tratamento.

Os dados foram levantados após 15 dias da primeira emergência, medindo-se diâmetro do colo e altura, tomando como referência a distância do colo ao ápice da muda, utilizando um paquímetro digital e uma régua de $30 \mathrm{~cm}$, respectivamente. Os dados foram tabulados Microsoft Word Excel 2010 e a estatística descritiva no sotfware no BIOESTAT, submetidos ao teste de normalidade de Lilliefors e para os dados paramétricos foi realizado as analises de variância de Tukey.

\section{Resultados e Discussões}

Conforme a tabela 1 observa-se que não houve diferença significativa no crescimento da parte aérea de Canavalia ensiformis (L.) DC. O trabalho realizado por ZANETTI (2003) avaliou o efeito do uso de misturas de fino de carvão e substrato comercial contendo fino de carvão na proporção de $100 \mathrm{~cm}^{3} \mathrm{dm}^{-3}$ no desenvolvimento de porta-enxertos de limoeiro 'Cravo', na qual também não houve influência significativa, porém, na proporção de $200 \mathrm{~cm}^{3} \mathrm{dm}^{-3}$ foram prejudiciais no desenvolvimento dos mesmos.

LIMA (2013) testou o biochar como substituto de matéria orgânica na formação de substratos para mudas, onde nos substratos com diferentes doses de esterco bovino apresentou valores superiores ao biochar e ao substrato comercial na melhora da qualidade das mudas. Em seu outro estudo sobre o desenvolvimento de mudas de beterraba em substratos comerciais tratados com 
biochar demonstram que existe uma redução no desenvolvimento das mudas dos tratamentos com maior quantidade de biochar (15\%), o que é discorrido em outros trabalhos onde o excesso desse produto pode chegar a prejudicar o desenvolvimento de algumas culturas.

Tabela 1. Estatística descritiva a partir das médias aritméticas da altura dos tratamentos de diferentes concentrações de biochar em plântulas de Canavalia ensiformis $(L)$.

\begin{tabular}{ccccc}
\hline & C0 & C1 & C2 & C3 \\
\hline Mínimo & 22,2 & 26,3 & 21,5 & 23 \\
Máximo & 29 & 32,7 & 33,1 & 29,3 \\
Média & 25,4 & 28,5 & 27,3 & 26,8 \\
\pm & \pm & \pm & \pm & \pm \\
DP & 2,79 & 2,93 & 5,63 & 2,71
\end{tabular}

Para o diâmetro do colo (Tabela 2) observa-se que entre a testemunha e o substrato com 254,25 g/balde de biochar, apresentaram o maior e mínimo valor entre os tratamentos. Comparando a CAVALCANTI (2012), houve uma pequena variação média, mas, ainda sim, o diâmetro do maracujazeiro aumentou conforme a concentração do biochar. SOUCHIE (2011) testou o carvão pirogênico como condicionante para substrato de mudas de Tachigali vulgaris L.G. Silva \& H.C. Lima e sua maior média para o diâmetro do coleto foi observada na maior concentração do carvão (50\%), chegando entre 2,5 a $3 \mathrm{~mm}$, valor menor do que o obtido na tabela 2.

Tabela 2. Estatística descritiva a partir de médias aritméticas do diâmetro do colo dos tratamentos de diferentes concentrações de biochar em plântulas de Canavalia ensiformis $(L)$.

\begin{tabular}{ccccc}
\hline & C0 & C1 & C2 & C3 \\
\hline Mínimo & 4,1 & 4,4 & 4,1 & 3,8 \\
Máximo & 4,7 & 4,6 & 5,1 & 5,5 \\
Média & 4,5 & 4,5 & 4,6 & 4,6 \\
\pm & \pm & \pm & \pm & \pm \\
DP & 0,26 & 0,08 & 0,45 & 0,70
\end{tabular}

. A seguir, a tabela 3 ilustra estatisticamente que não houve diferença significativa nas médias das alturas e do diâmetro pelo teste de Tukey.

Tabela 3. Valores médios da altura e diâmetro dos tratamentos com diferentes concentrações de biochar. 


\begin{tabular}{lll}
\hline C0 & $25.33334 \mathrm{a}$ & $4.47500 \mathrm{a}$ \\
$\mathrm{C} 2$ & $28.47917 \mathrm{a}$ & $4.47500 \mathrm{a}$ \\
$\mathrm{C} 3$ & $27.28125 \mathrm{a}$ & $4.63333 \mathrm{a}$ \\
$\mathrm{C} 4$ & $26.78125 \mathrm{a}$ & $4.56667 \mathrm{a}$ \\
\hline
\end{tabular}

*Médias seguidas de mesmas letras não diferem entre si pelo teste pelo teste Tukey.

Segundo PETTER (2012), altas concentrações de biochar podem chegar a prejudicar a respiração das células em virtude do maior acúmulo de água no substrato, alterando as características físicas do substrato, principalmente a porosidade, uma alternativa para explicar os resultados obtidos neste trabalho. A mistura de substrato (esterco + areia + biochar) pode não ter sido favorável para o desenvolvimento significativo da espécie, uma vez que o biochar atua na retenção de água e não disponibilizando nutrientes, portanto o aumento na sua concentração poderá ter acarretado diminuição na sua quantidade de nutriente disponível.

\section{Conclusões}

A espécie Canavalia ensiformis (L.) não sofreu influência do biochar, contrapondo-se a algumas bibliografias que apresentaram influência positiva com a adição do carvão vegetal no solo, necessitando estudos para as e doses ideias para cada tipo de cultura, considerando seus benefícios já comprovados.

\section{Referências}

ALVES, M.; Impactos da utilização de fino de carvão e extrato pirolenhoso na agricultura; jaboticabal - São Paulo - Brasil julho de 2006.

ALMEIDA, E. L.; MARCOS, F. C. C.; SCHIAVINATO, M. A.; LAGÔA, A. M. M. A.;ABREU, M. F.; crescimento de feijão-de-porco na presença de chumbo; Bragantia, Campinas, v.67, n.3, p.569-576, 2008.

ATKINSON; C. J.;FITZGERALD, J. D.;HIPPS, N. A.;Potential mechanisms for achieving agricultural benefits from biochar application to temperate soils: a review; December 2010, Volume 337, Issue 1-2, pp 1-18.

BENITES, V. M.; TEIXEIRA, W. G.; REZENDE, M. R.; PIMENTA, A. S.; Utilização de carvão e subprodutos da carbonização vegetal na agricultura: aprendendo com as terras pretas de índio.

BRITO, J. O; L. E. G. BARRICHELO e F. SEIXAS; Análise da Produção Energética e de Carvão Vegetal de Espécies de Eucalipto; ESALQ - USP, Depto. de Silvicultura - 13.400 - Piracicaba - SP. CAMPOS, F.; Carvão no solo aumenta a produtividade; Painel Floresta 2015. 
CAVALCANTE, L.; HERBERT, I.;PETTER; F. A.;ALBANO; F. G.; SILVA, R. R. S.;DA SILVA JÚNIOR; G. B.;Biochar no substrato para produção de mudas de maracujazeiro amarelo; Revista de la Facultad de Agronomía, La Plata (2012) Vol 111 (1): 41-47.

LIMA' S. L.;MARIMON-JUNIOR’ B. H.;PETTER; F. A.;TAMIOZZO, S.;BUCK; B. B.; MARIMON ${ }^{\mathrm{I}}$; B. S.; biochar as substitute for organic matter in the composition of substrates for seedlings; Acta Sci., Agron. vol.35 no.3 Maringá July/Sept. 2013.

LÓPEZ, R. R. S.;Canavalia ensiformis (L.) DC (FABACEAE); Laboratorio de química de produtos naturais, instituto de tecnologia de fármacos, FIOCRUZ, Avenida Brasil 4365, Manguinhos, Rio de Janeiro, RJ, Brasil.

MENDONÇA, V.; ARAÚJO NETO, S. E.; RAMOS, J. D.; PIO, R.; GONTIJO, T. C. A.; diferentes substratos e recipientes na formação de mudas de mamoeiro 'sunrise solo'; Rev. Bras. Frutic., Jaboticabal - SP, v. 25, n. 1, p. 127-130, Abril 2003.

MORAES, L. M.; CAVAlCANTE, L. C. D.; FARIA, R. T.; Substratos para aclimatização de plântulas de Dendrobium nobile Lindl. (Orchidaceae) propagadas in vitro; Maringá, v. 24, n. 5, p. 1397-1400, 2002.

NÓBREGA, I. P. C.;Efeitos do Biochar nas propriedades físicas e químicas do solo: - Sequestro de carbono no solo; Dissertação para obtenção do grau de Mestre em Mestrado em Engenharia do Ambiente; Lisboa, 2011.

PAZ, E. J. J.; SOUZA, L. D.; BRITO, R. B. F.; A utilização do carvão vegetal como condicionador de solos; $7^{\mathrm{a}}$ Jornada Científica - Embrapa Mandioca e Fruticultura, 2013.

PETTER, F. A.; MARIMON JUNIOR, B. H.;ANDRADE, F. R.;SCHOSSLER, T. R.; GONÇALVES, L. G., MARIMON, B. S.; Biochar como condicionador de substrato para a produção de mudas de alface; Dourados, v.5, n.17, p.243-250, 2012.

SOUCHIE; F. F.;MARIMON JUNIOR; B. H.; PETTER; F. A.;MADARI; B. E.;MARIMON; B. S.; LENZA; D.; CARVÃO PIROGÊNICO COMO CONDICIONANTE PARA SUBSTRATO DE MUDAS DE Tachigali vulgaris L.G. Silva \& H.C. Lima; Ciência Florestal, Santa Maria, v. 21, n. 4, p. 811-821, out.-dez., 2011.

ZANETTI, M.;CAZETTA, J. O.; MATTOS JÚNIO, D.; CARVALHO, S. A.; USO DE SUBPRODUTOS DE CARVÃO VEGETAL NA FORMAÇÃO DO PORTAENXERTO LIMOEIRO 'CRAVO’ EM AMBIENTE PROTEGIDO; Rev. Bras. Frutic., Jaboticabal - SP, v. 25, n. 3, p. 508-512, dezembro 2003. 